\title{
Review
}

\section{A Review on the Effect of Delamination on the Performance of Composite Plate}

\author{
Muhammad Imran*, Rafiullah Khan and Saeed Badshah \\ Department of Mechanical Engineering, International Islamic University, Islamabad, Pakistan \\ (received April 8, 2018; revised May 17, 2018; accepted May 22, 2018)
}

\begin{abstract}
Composite materials are the utmost widely used materials and terms of their strength to weight ratios make them most attractive materials for aerospace applications and other high load bearing structures where strength to weight ratio is critical. In the preliminary designs of aircraft components, laminated composites subjected to compressive loadings play a vital role and their performance is one of the most important parameters. This paper presents a comprehensive review on the performance of composite structures subjected to buckling loads and other behaviours. This review also lightens some of the attempts to understand the buckling behaviour of composite plates by numerical and experimental methods.
\end{abstract}

Keywords: buckling analysis, composite plate, delamination

\section{Introduction}

Mankind has discovered and developed several materials which suit its various purposes. There are very few materials which have wide range of applications. One of those rare materials is fibre reinforced polymer (FRP) composites (Imran et al., 2018a; 2018b; Imran, 2015). It is an advanced product of engineering work. This material is very light weighted but it has fairly high specific stiffness and strength which makes it very desirable for the aerospace technology. The very first time, this material was employed in 1940s for the construction of airplanes and ships (Imran et al., 2018b; Barbero, 2017). This material is unique because it is non-magnetic, energy absorbent, and non-corrosive (Imran et al., 2018b; Bakis et al., 2002). These characteristics make it a fine choice for automobiles (Subramani, 2017), and building structure because it can absorb the energy from the ground to reduce the impact of the earthquake. Currently, aircraft industry is commonly using composite material because it has light weight. The wing structure and fuselage of the airbus A350 XWB were constructed from the reinforced fibre plastic known as CFRP (Tavares and Castro, 2017) shown in Fig. 1. This was the first airbus to use the FRP composites.

The aim of this paper is to analyse the buckling behaviour of fibre reinforced polymer composites and delamination effect on this buckling. The testing methods and optimi-

*Author for correspondence:

E-mail: muhammad.imran@iiu.edu.pk zation methods of the laminates of these composites will also be reviewed in this article.

Analysis of the buckling behaviour of composite plate. There are two levels to investigate the laminates composite material's mechanical behaviour. These two levels are large scale macro mechanics and small scale micromechanics. In case of small scale micromechanics, representative volume (RVE) analysis is used to define the relationship between each lamina and its constituent material. This analysis assumes that properties of

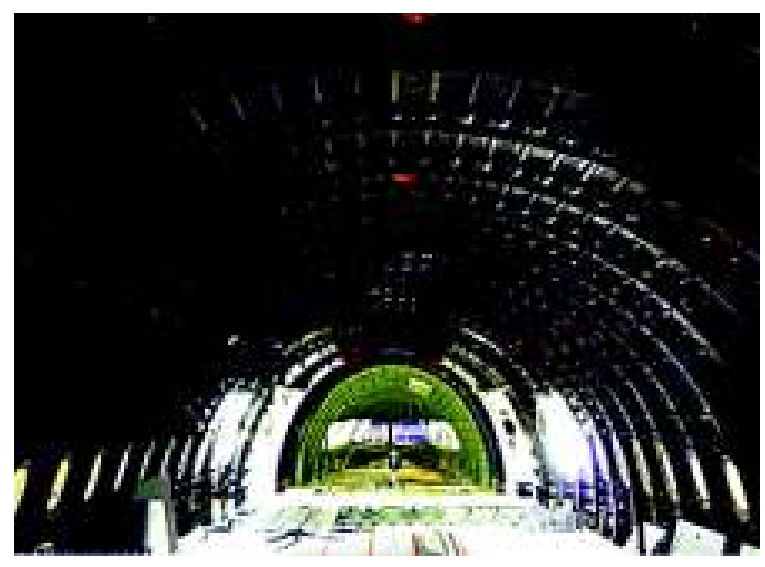

Fig. 1. The A350 XWB is the first airbus with fuselage and wing structures fibre-reinforced made plastics (CFRP) (Bakis et al., 2002). 
individual layers are already known and this analysis focuses on the effects of individual layers of the composite material on each other and entire laminate. On the contrary, in case of large scale micro-mechanics the interface between matrix and fibre is ignored because it is considered that each lamina in the composite material is homogeneous/orthotropic. Currently, macro mechanics is used in the designing of composite laminates because macro mechanical equations of this type of designing are well established therefore macro mechanics is also used to analyse buckling of composite plates.

Buckling is one of the most prominent issues in the laminated composite materials. This buckling behaviour is under study for several years and it is more likely to
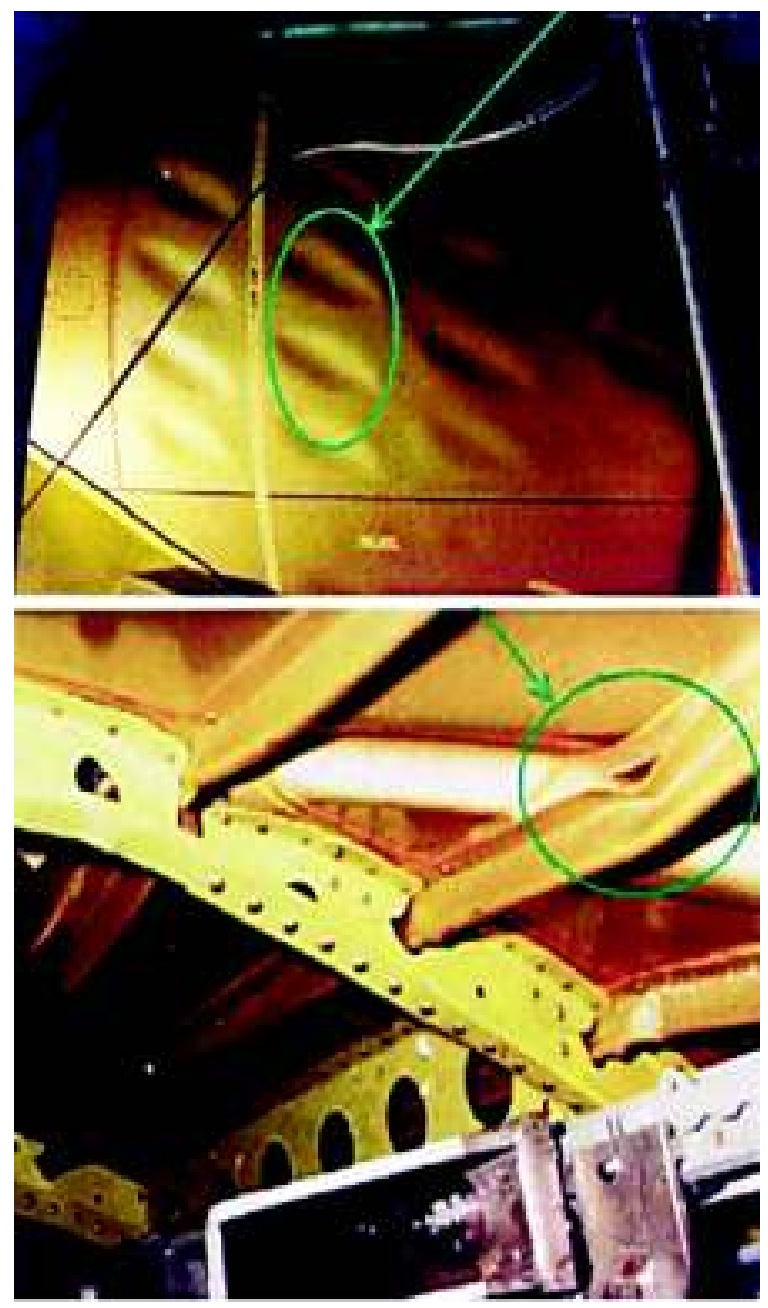

Fig. 2. Local buckling in airplane fuselage (Belesis and Labeas, 2010). occur in materials with thin-walled design. FRP composites also have thin-walled design because it contains polymer which has low stiffness and fibres which have very high strength due to which, FRP are susceptible to global and local buckling even before the failure of strength of the material as shown in Fig. 2.

Leonhard Euler is the pioneer of investigating buckling in laminates. He studied the stability of the compressed and flexible columns in the composite material. These assumptions are that columns are either straight or have known curvature and cross sections of these columns are uniform. When the structure faces the in-plug compression load its plates do not displace until that compression load reaches the critical buckling load denoted by $P_{c r}$. After this point failure occurs and this failure is referred as buckling. It is important to understand few terms and conditions to further investigate the buckling behaviour (Bakis et al., 2002).

$\mathrm{Le} / \mathrm{k}=$ slenderness ratio (This ratio relates the cross section's radius of gyration to the effective length of strut).

$$
\begin{aligned}
& \mathrm{K}=\text { radius of gyration } \\
& \mathrm{k}=\sqrt{\frac{1}{\mathrm{~A}}}
\end{aligned}
$$

$\mathrm{Le}=$ the effective length of the strut If $\frac{L_{e}}{\kappa}<0.3 \sqrt{\frac{\pi^{2} E}{\sigma_{y c}}}$ then the strut will be thick and compressive theory will be applied

If $\frac{L_{e}}{\kappa}<2 \sqrt{\frac{\pi^{2} E}{\sigma_{y c}}}$ then the strut will be thin and buckling theory will be applied

Here $\sigma_{\mathrm{yc}}=$ comprehensive yield stress

The classical laminated plate theory (CLPT) is used to analyze the plate buckling (Barbero, 2010). Figure 2 is showing the lamens under biaxial compression. Here, it is assumed that the material is symmetric and it is made up of plies with $\theta=45^{\circ}$. T is the thickness of all plies and there are $\mathrm{N}$ plies in the composites. The critical value $\left(\mathrm{A}_{\mathrm{cr}}\right)$ is the threshold. The load beyond this level will cause buckling. Figure 3 is showing the scheme of biaxial loading and geometry of plates (Haftka and Walsh, 1992).

where:

$\mathrm{h}=$ thickness of laminates; $\mathrm{z}=$ distance from the plate of symmetry; $\theta=$ ply-orientation angle; $\mathrm{P}_{\mathrm{k}}=$ variable 

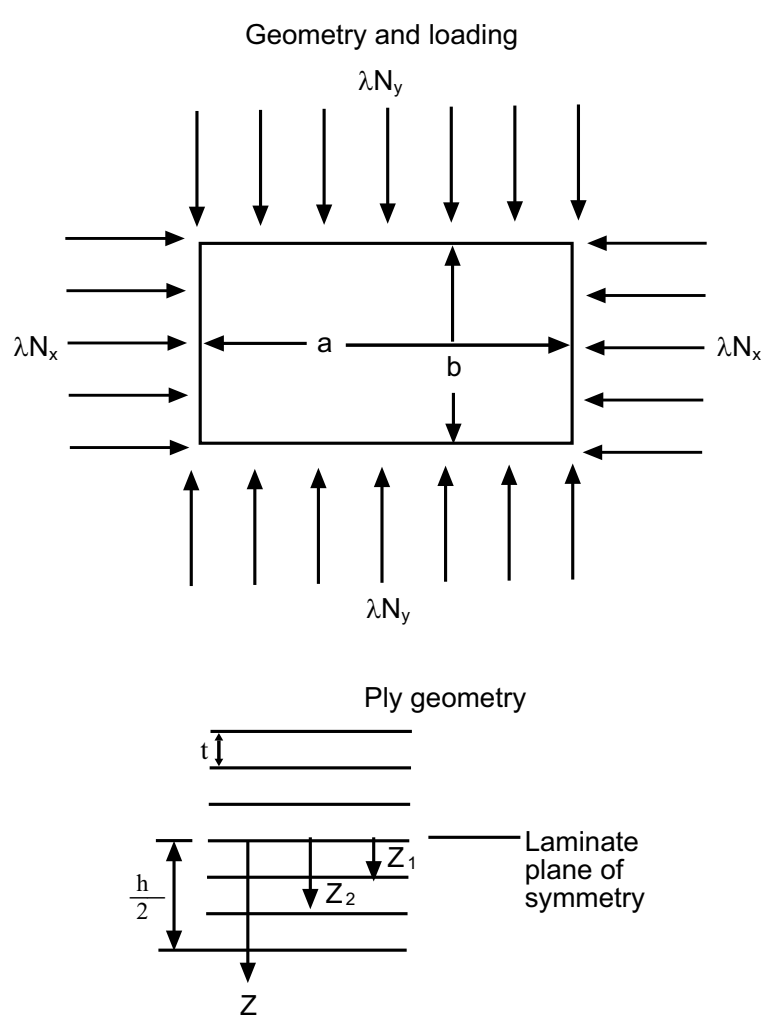

Fig. 3. The geometry of laminated plate and biaxial loading scheme (Haftka and Walsh, 1992).

whose value is 1 if kth ply is occupied. Its value is if $0^{\text {th }}$ ply is empty.

There are two ways for plates to buckle as per the intensity of bending energy. These two ways are limit point buckling and bifurcation buckling. The instability points are referred as the bifurcation buckling and these points occur at the intersection of two equilibrium points. Limit point buckling occurs when strain energy releases and negative stiffness occurs. The equilibrium path does not change abruptly during limit point. If the load keeps on increasing then there are chances that structure will snap towards out of the plane displacement curve. This phenomenon is known as the snap-through buckling because it creates a whole new equilibrium position for the structure. The curve between out of plane displacement and load show zero slope at maximum load point. This point is referred as maximum load $\left(\mathrm{P}_{\mathrm{or}}\right)$ or limit point. There are three types of buckling analysis which are:

- Classical buckling analysis

- Difficult classical effects

- Non-classical phenomenon
Figure 4 is showing some curves. Curves number 1, 2 and 3 define the classical buckling analysis. In these curves $\mathrm{n}$ is the in-plane loading force and $\mathrm{w}$ is the out of the place displacement. If the load is applied at the middle of the plate and plate is perfectly symmetric then out of plane displacement will not occur in this situation. As per the curves 1 and 2 the loading on the plates can increase to the yield point but bifurcation will occur if stability happens at $\mathrm{N}=\mathrm{N}_{\mathrm{cr}}$. It means buckling will occur and important thing to note here is the $\mathrm{N}_{\mathrm{cr}}$, which is a perturbation, will be created out of the plane displacement. Euler buckling is generalized into critical linear analysis and it indicates that $\mathrm{w}$ number of jumps happen to the infinity at the point $\mathrm{N}=\mathrm{N}_{\mathrm{cr}}$. This phenomenon is shown in the curve 3. After displacement nonlinear effect occurs and it increases further to next level. In this case plates can sustain the load beyond the critical point $\mathrm{N}_{\mathrm{cr}}$ before collapsing. This phenomenon is shown in the curve 4 . This curve is known as the post buckling curve.

The second type, difficulty classical effect, arises when non-homogeneous variable thickness, nonlinear relation between stress and strain, shear deformation, springs, and vibrations are present in the structure.

The non-classical analysis of buckling involves the investigation of dynamic effects of loading, non-elastic behaviour, and imperfections. The Fig. 4 is showing 5 curves and buckling behaviour will follow the path of these curves if the plates have symmetry or flatness. It is impossible to distinguish buckling point in this case. The deviation in the plates or of the plates disturbs

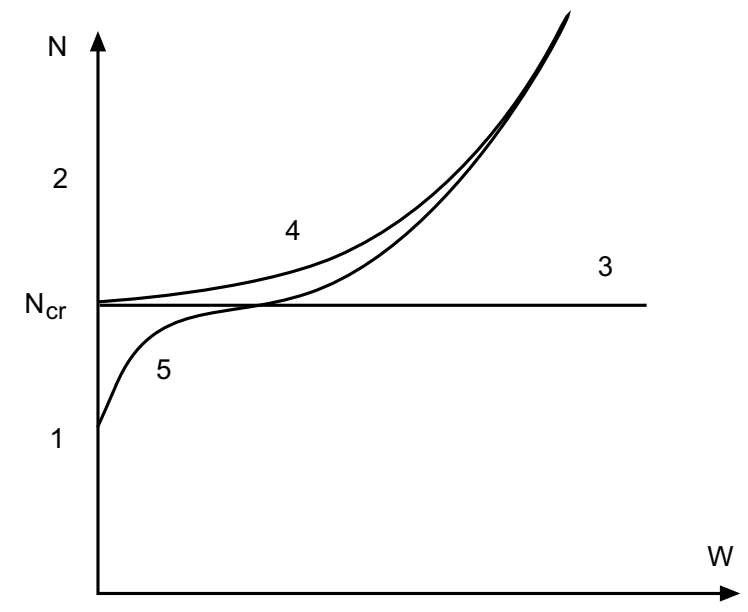

Fig. 4. Variation of displacement versus in plane load (Beznea and Chirica, 2011). 
the symmetry and this deviation is referred as delamination and traversal imperfection (Beznea and Chirica, 2011).

Local buckling is also studied by several scholars. Reddy et al. (1985) studied that the beams of tin epoxy/ graphite I is studied under axial compression. FRP beams are studied with both thin-walled close and open conditions by Tarján et al. (2009). The resistance toward buckling can be increased through optimization. This optimization is studied by Onoda (1985) for laminated cylindrical shells which were undergoing axial compression. The fundamental frequency of the composite material, thin-wall, is studied through torsional and bending modes. Starnes et al. (1985) studied that the post-buckling behaviour was of curved graphite panel and it was studied through analytical and experimental methods. The panel was going through axial compression in that study. The crippling and post-buckling of shallow curve laminates are studied by Arnold et al. (1986). In this study only the edges of the plates were stiffened. In a study by Bisagni and Lanzi (2002), neutral methods are used to optimize post-buckling in the stiffened composite panels. Stevens et al. (1995) analysed both buckling and post-buckling. In another study by Bambach (2009), edge-stiffened material was used to inspect the photography measurements of interaction in channels and buckling behaviour.

Figure 5 is showing the load-displacement scheme when buckling occurs in the isotopic plates and this issue was reported frequently. These schematic diagrams in Fig. 5 follow the trend which is portrayed.

There are several effects which play an important role in the buckling behaviour of the plates. These effects include second order effect, plasticity, and initial imperfection (Van der Burg, 2011). In this research Euler plate buckling stress $\left(\sigma_{\mathrm{cr}}\right)$ is measured against plate slenderness. This is the stress level at which perfect plate experiences buckling if the material is elastic.

Calculated buckling load of rectangular laminates composite plates undergoing biaxial and in plate uniaxial loading. Von Karman type nonlinearity and first order shear deformation theory is used for this purpose. The impact of fibre orientation angles. These angles affect the critical and non-dimensional loads. In this experiment the critical load was higher at $\theta=0^{\circ}$ and aspect ratio of CSCS plates was 0.5 . These plies were subjected to $\mathrm{x}$-axis directed uniaxial loading. The $\mathrm{y}$-axis directed critical loading occurred at zero degree and biaxial load occurred at $55^{\circ}$ (Shukla et al., 2005).

The connection between non-directional critical load and fibre orientation angle for four different layers of CSCS square plates have asymmetric angle-ply. Micro cracking occurs in this situation but laminate can reach a strain even before the happening of micro cracking. This strain depends on the characteristics of the resin system. If the resin system is brittle like that of polyester then this point of strain can occur way before the failure of laminates. Fibres in the structure also play important
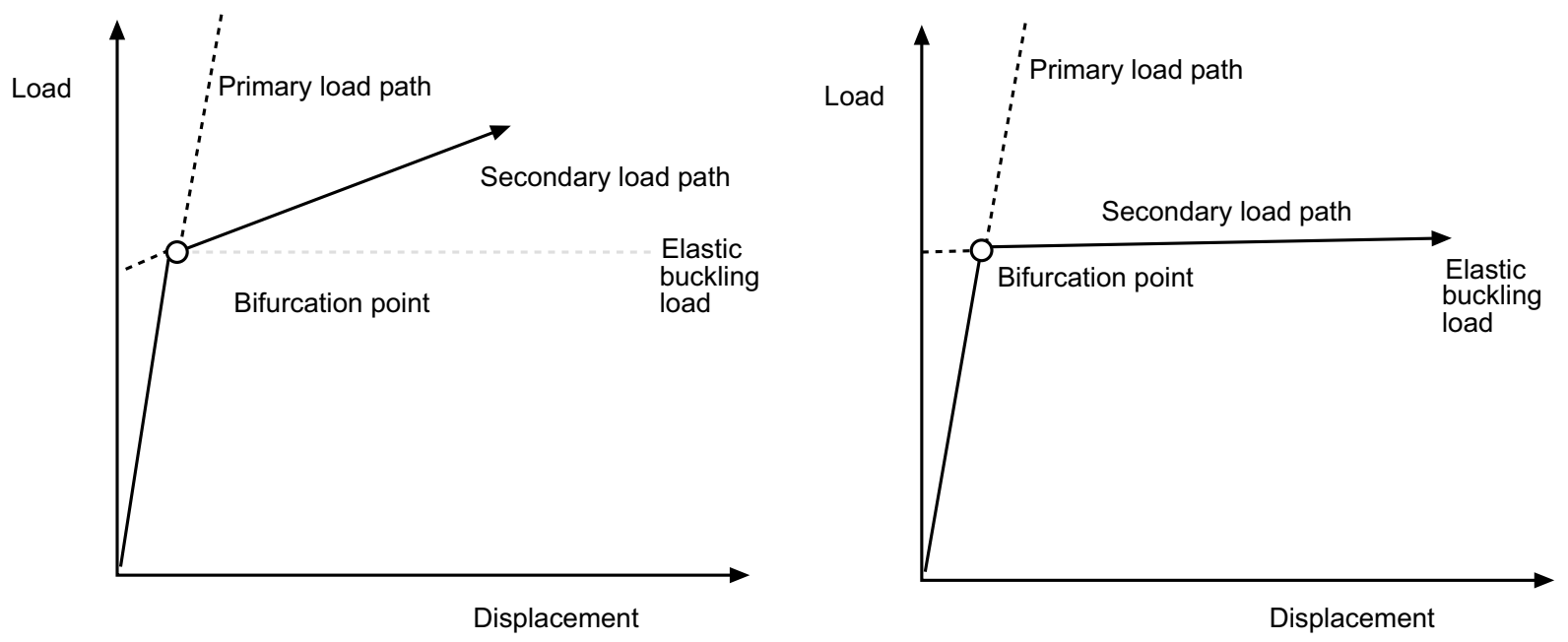

Fig. 5. The ideal load-in plate displacement diagram of a plate (left) and a column (right) for elastic buckling (Van der Burg, 2011). 
role in the strength of the material therefore, micro cracks of resin do not weaken the structure right away. Here it is important to note that the resin should be able to distort as much as fibre in order to achieve same component's complete mechanical properties when laminates experiences tension (Shukla et al., 2005).

Effect of delamination on buckling performance of FRP composite plates. In laminated materials, delamination is a type of deformation of layers. It can be caused by repeated pressure or stresses on the material. In-service failures can cause this type of failure. The imperfect curing processes put irregular pressure on different areas and create delami-nated areas. The presence of these delaminated spots in the material can lose its strength during compressive loading due to the buckling of the laminated structure. There are different models of this mode of failure; one of the most common is the interlaminar delamination. In thin-walled laminated FRP material, the structural stability is a serious issue and buckling in the structure can cause catastrophic results therefore this model of failure should be considered during the design phase (Hwang and Mao, 2001). In-plane, the delaminated structure faces the compressive dominated load which can create the local buckling of the laminates even before the global buckling of the composite. Sometimes the mixed mode of buckling also occurs. In this mode, both local and global buckling occurs in the laminated composite. In the mode of failure, it is recommended to analyse the delamination after the buckling (Hwang and Mao, 2001).

A delaminated circular plate was used to carry out its elastic post-buckling analysis using asymmetric compression. This analysis was done along the clamped boundaries of the plate and it was evaluated by Chen and Bai (2002) and Yin and Fei (1988) who used the debond sandwich plates to describe the post-buckling behaviour. This behaviour was described in the face/core interface. Avilés and Carlsson (2007) described this behaviour in the sandwich panels. Debond composite is also described after exposing them to the in-plane compression. They predicted the initiation of propagation and debonding of sandwich panels through nonlinear FEM analysis. Cappello and Tumino (2006) studied the post-buckling and buckling behaviour of the cross-ply and unidirectional plates. They investigated multiple delaminations through numerical analysis. Wang and Dong (2007) took laminated shells' cylinders and made the delamination of lemniscates and triangular shapes close to the surface of those cylindrical plates. They investigated the hydrothermal effects on the local buckling of these delaminated areas through numerical analysis.

The research work of Parlapalli and Shu (2004) is about the analysis of two layer beam's buckling behaviour. The beam has a single asymmetric delamination. This delamination was clamped and they only analyzed the boundary conditions. According to Kyoung et al. (1998), the cross-ply composites are used with several delaminations to investigate both post-buckling and buckling. An embedded delamination was created in the laminates to study the post-buckling and buckling behaviour. They used finite element analysis for the investigation. They found that if the buckling size is smaller than the buckling load then it does not affect the post-buckling behaviour but when the size of delamination increases it also decreases the buckling load.

Tri-layer beams were analysed by Parlapalli and Shu (2004). Those beams had symmetrical enveloped delaminations and they used classical engineering solutions to examine the beam's buckling behaviour. They found that shorter enveloped delamination do not affect the critical buckling load but this load is sensitive to longer enveloped delamination. Aslan and Sahin (2009) examined the compressive behaviour and buckling behaviour of laminates with several delaminated region. The findings indicated that the near-surface and large sized delamination affect the compressive failure load and critical buckling load of the structure. The size of delamination far from the surface does not greatly affect the compressive failure load and critical buckling load of the composite laminates.

The diameter of critical delamination of composite plates was studied by Arman et al. (2006). The composite plates were studied under buckling loads. They found a relationship with the diameter of delamination and critical buckling load because this load decreased when the diameter of delamination increased to a certain value. They also examined fibre orientation and its effects on the buckling load. The buckling and postbuckling behaviour of cylindrical shells of composite laminates are studied by Tafreshi (2004) under highpressure condition. They also found that small area of delamination does not affect the buckling load but the critical load of the buckling reduces greatly when the size of delamination increases or it is closer to the surface of the laminates. The stacking sequences of the laminates which support the growth of delaminations 
highly influence the buckling load. The structure which shows high resistance to delamination does not affect the buckling behaviour (Tafreshi, 2004). The overall conclusion of these studies is that the delamination in the structure reduce the buckling load especially when they are closer to the surface.

Common non-destructive testing methods used for evaluation of damage in FRP laminates. Damages in the FRP can be identified with the help of non-destructive tests (NDT). These tests are used when the material selected adequately and the processes of designing and manufacturing are completed successfully. In this scenario visual inspect and non-destructive tests are used as the first phase to check the quality of the final product. These methods are effective because they help organizations to keep quality high without damaging the product and incepting high cost. Two most common techniques for non-destructive tests are computer thermography and infrared thermography. Both of these methods are discussed here in detail.

a) Infrared thermography. Thermography is a field of science which measures the temperature on the surface of a given material to investigate the changes in the temperature. The temperature on the surface of the material can be increased through stress or excited source of heat. Usually heat transfers uniformly throughout the surface with a perfect structure. If the temperature at different points of the surface is different then it indicates that there is some abnormality in the structure. The principle of thermography is simple but the question is how to observe or visualize the changes in temperature. Infrared (IR) rays and television photography can be used for this purpose and this process is known as thermal imaging. The wavelength of infrared rays varies from $0.9 \mu \mathrm{m}$ to $1 \mathrm{~mm}$. It is relatively difficult to detect the faults in the material with higher thermal conductivity like CFRP. Transient heat transfer and rapid scanning are used as a remote monitoring technique. In this process, thermal fields are scanned on the TV compatible with IR images. This process is the base of pulse video thermography (PVT) (Harris, 1999).

There are several methods to analyze the strain on the laminated composite plates; one of those methods is IR thermography. Johnson (2006) reported that quantitative IR thermography is used to test the fatigue loading in the GFRP. The technique of thermoelastic stress analysis (TSA) is used to define a relationship between IR emission and the deformation of the surface of the laminates in order to visualize and interpret the results.
IR thermography is also used to test bonded single lap joints to spot the stress concentration. In this technique data is acquired through the schematic of TSA and IR camera is used to capture the image of the surface at the speed of 400 frames per second (Johnson, 2006). They synchronized the images through load signals to get the images corresponding to the maximum loading values. They used quantitative IR thermography to measure fatigue damage in GFRP laminates. The quasiisotropic specimen is used and life cycle of fatigue damages of this specimen. The damage of this specimen was due to the delamination and matrix cracking close to the surface. The expansion of these damages led to the fibre orientation. At the last $90,505^{\text {th }}$ cycle, the stress concentration is below the mark. The in-phase is signal of TSA. This signal is for the area near the crack tip. Eccentrically loaded single-edge-notched (tension), also referred as $\operatorname{ESE}(\mathrm{T})$, specimens with thick protruded section is used in the test. The shapes in the figure are showing the stresses in the material. The location of the stress and tip of the crack can be located when the crack propagates toward failure (Johnson, 2006).

Sultan et al. (2013) reported that the thickness and depth of the delamination in the GFRP laminates are determined. The delamination was introduced artificially at various thicknesses and at several lengths. They inserted aluminum between different layers to introduce delamination artificially. Delamination acts as the barrier to heat and sends heat back to the front surface if heat is transferring from front to rare surface. It results in the higher temperature at areas with delamination and offers a fine way to detect the fault. Boritu et al. (2011) and Sultan et al. (2012) reported the detection of delamination through thermography.

b) Computer tomography. Computer thermography, also known as CT scan, is used to detect the fault in the material using $\mathrm{X}$-rays. These rays pass through the material at different angles and fall on the receiver which then generates three-dimensional image of the object. All faults including cracks, delamination, and fibre breakage are visible. The pine tree shaped effect is showing the growing delamination which is progressing deep into the material and growing big. The oblong delamination is the main cause of this fault (Amos, 2011). They used both CT and IR thermography to detect the damages in the buckled laminates of GRRP.

Optimisation method of composites laminate. Optimisation of the buckling laminates is the selection of most favourable stacking sequence because this sequence 
significantly affects the critical buckling load of the composite laminates. In the process of optimisation, a large number of different factors plays their roles and it is important to understand those parameters and develop the sequence accordingly. Some of these parameters include:

- Types of design variable like discrete, continuous, and mixed

- Global and local optima

- Number of design variables

- Shape of practical design space

- Number of constraints

- Constrained problems

- Unconstrained problems

- Objective function's type like linear or nonlinear

All these parameters should be considered to optimise the composite laminates. There are four methods to optimise the laminated FRP plates. All these four methods are discussed below.

Enumeration or exhaustive search method (ESM). The exhaustive or enumeration method is used to optimise the design after analyzing all possible combinations of design variable. The best combination is then selected after setting the criterion to assess the design. This method is very effective as it has the ability to provide the best global solution and lightest composite structure (Ghiasi et al., 2010; Verette, 1970).

There are several exhaustive and probabilistic computational based techniques which are currently used in the construction sector. These techniques have provided several innovative and interesting results to revolutionize the construction sector.

Sequential quadratic programming (SQP). SQP is mathematical programming which uses the rules of mathematics and computational power of computing machines to optimise the design. SQP has been examined and discussed thoroughly but it is not widely applied in laminated composite structures so far (Boggs and Tolle, 1995).

Besides SQP, there are some other continuous optimisation methods which are explained comprehensively in different studies. These methods include:

- Newton's method

- Nonlinear programming's duality theory

- Primal-dual interior points method

- Semi-definite programming
- Steepest descent algorithm

- Line search method

- Unconstrained problems method

- Rate of convergence method

SQP has been explained by several researchers who used basic theories to explain it (Gill and Wong, 2012; Morales et al., 2011; Bomze et al., 2010).

Genetic algorithm (GA). The generic algorithm is an advanced and powerful tool to optimise functions (Deb, 2001; Golberg, 1989). This tool is simple in its approach as it looks for the improvements in the consecutive generations of the given function (Nagendra et al., 1992). The word "genetic" is used for this algorithm because it mimics the natural survival extinct of living organisms. Humans and other existing species went through the process of evolution at some level. This algorithm also evolves the solution as per the requirements. This algorithm also employs the mechanism of population genetics to get the results. The best thing about GA is that it does not require the differentiability of constraints and objective functions (Nagendra et al., 1992). In the case of laminated composite plates, the best design is the one which possesses fixed number of plies for laminate stiffness and strength. Kogiso et al. (1994) reported the tournament selection scheme that was employed for the selection process. The crossover probability of 0.75 and $0.1 \%$ of mutilation probability was used in single point crossover. The design requirements were stored in the memory of GA. The requirements were about the ply, buckling, and strength conditions of least depth laminates.

According to Muc and Gurba (2001) GS is used to optimise the layout of the composite with finite elements and objective function. Sivakumar et al. (1999) studied that composite structure with cut outs going through big amplitude oscillations is optimised through GA. There are several aspects of GA which are similar to other such algorithms but GA is better in all those aspects. The problems of vibrations, buckling, and bending are also studied by several researchers through closed form of solutions.

In some cases, closed-form solution are not feasible. In such cases FEM is used to optimise the structure. There are some important factors which affect the buckling load and it is important to investigate those factors for applying GA. These factors are the crossover, mutation probabilities, aspect ratio, and cut-out size. The phrase 
"survival of the fittest" is best suited to explain the evolutionary optimisation technique. It increases the number of solutions through this technique. GA works best with the suitably large magnitude if the local optimisation is required. In the case of global optimisation, unlimited numbers of iterations are required to get success. GA has high cost but still is the most commonly used method to optimise the stacking sequence of composite plates (Soremekun et al., 2001).

Yoshikawa et al. (2008) and Naik et al. (2005) thoroughly investigated the GA but they are not the first one to do so. The research work of Erdal and Sonmez (2005) analyzes the optimum weight of composite plates and the effects of load on it. They selected the line B region of fibre breakage and set different failure criteria in this region to get result.

They performed the optimisation of laminates to minimize the weight of the structure. Their selected failure criteria included Tsai-Wu (TW), maximum stress (MS), and failure mechanism based (FMB). The results indicate that the increase in load does not affect the weight of the laminates too much (Erdal and Sonmez, 2005).

Simulated annealing (SA). Simulated annealing is a unique method to optimise the laminated composites but it focuses on the annealing of the structure. It starts the process using the greedy search. This search method brings out unfavourable solutions too if they satisfy the conditions of temperature parameter. Initially, the probability of accepting the unfavourable solution remains high but it starts decreasing gradually through cooling schedule as defined by the users (Lombardi et al., 1992). This method of optimisation gives the best solution and after genetic algorithm method, it is the most commonly used technique (Arvin and Bakis, 2006; Sadagopan and Pitchumani, 1998; Sargent et al., 1995; Lombardi et al., 1992).

\section{Conclusion}

The review shows that there is lot of research work going on buckling analysis of composite plates to understand the various parameters to avoid failure of composite materials under compressive loading. Finite element analysis and classical bifurcation method are used to study buckling by several researchers over the last few years and they found very interesting results. They developed equations for the critical buckling. These equations work for perfect plates for various edge conditions. Buckling phenomenon is the breakdown of the structure of the composite but out of plane displacement usually occurs after the bifurcation. The buckling behaviour depends a lot on the material and structure of the composite. The way of loading also plays its role in it.

\section{References}

Amos, M. 2011. Advanced Industrial X-ray Computed Tomography for Defect Detection and Characterisation of Composite Structures. Ph.D. Thesis, University of Manchester, UK.

Arman, Y., Zor, M., Aksoy, S. 2006. Determination of critical delamination diameter of laminated composite plates under buckling loads. Composites Science and Technology, 66: 2945-2953.

Arnold, R., Hussain, A., Mayers, J. 1986. Buckling, postbuckling, and crippling of shallow-curved composite plates with edge stiffeners. Journal of Aircraft, 23: 589-598.

Arvin, A.C., Bakis, C.E. 2006. Optimal design of pressfitted filament wound composite flywheel rotors. Composite Structures, 72: 47-57.

Aslan, Z., Sahin, M. 2009. Buckling behaviour and compressive failure of composite laminates containing multiple large delaminations. Composite Structures, 89: 382-390.

Avilés, F., Carlsson, L. 2007. Post-buckling and debond propagation in sandwich panels subject to in-plane compression. Engineering Fracture Mechanics, 74: 794-806.

Bakis, C.E., Bank, L.C., Brown, V., Cosenza, E., Davalos, J., Lesko, J., Machida, A., Rizkalla, S., Triantafillou, T. 2002. Fibre-reinforced polymer composites for construction-state-of-the-art review. Journal of Composites for Construction, 6: 73-87.

Bambach, M. 2009. Photogrammetry measurements of buckling modes and interactions in channels with edge-stiffened flanges. Thin-Walled Structures, 47: 485-504.

Barbero, E.J. 2017. Introduction to Composite Materials Design. 534 pp., $3^{\text {rd }}$ edition, CRC Press, USA.

Barbero, E.J. 2010. Introduction to Composite Materials Design. 562 pp., $2^{\text {nd }}$ edition, CRC Press, USA.

Beznea, E.F., Chirica, I. 2011. Buckling and postbuckling analysis of composite plates. INTECH Open.DIO:10.5772/13741.

Bisagni, C., Lanzi, L. 2002. Post-buckling optimisation of composite stiffened panels using neural networks. Composite Structures, 58: 237-247. 
Boggs, P.T., Tolle, J.W. 1995. Sequential quadratic programming. Acta Numerica, 4: 1-51.

Bomze, I.M., Demyanov, V.F., Flectcher, R., Terlaky, T. 2010. Nonlinear Optimization, G.D. Pillo and F. Scheon (eds.), pp. 165-214, Springer, Germany. Boritu, A., Anghel, V., Constantin, N., Gãvan, A., Pascu, A. 2011. Non-destructive inspection of composite structures using active IR-thermography methods. UPB Science Bulletin Series D, 73: 71-84.

Cappello, F., Tumino, D. 2006. Numerical analysis of composite plates with multiple delaminations subjected to uniaxial buckling load. Composites Science and Technology, 66: 264-272.

Chen, H., Bai, R. 2002. Postbuckling behaviour of face/core debonded composite sandwich plate considering matrix crack and contact effect. Composite Structures, 57: 305-313.

Deb, K. 2001. Multi-objective Optimization using Evolutionary Algorithms. John Wiley \& Sons, New Yark, USA. ISBN:047187339X

Erdal, O., Sonmez, F.O. 2005. Optimum design of composite laminates for maximum buckling load capacity using simulated annealing. Composite Structures, 71: 45-52.

Ghiasi, H., Fayazbakhsh, K., Pasini, D., Lessard, L. 2010. Optimum stacking sequence design of composite materials Part II: Variable stiffness design. Composite Structures, 93: 1-13.

Gill, P.E., Wong, E. 2012. Sequential Quadratic Programming Methods. Mixed Integer Nonlinear Programming. pp. 147-224, Springer, Germany.

Golberg, D.E. 1989. Genetic Algorithms in Search, Optimization, and Machine Learning. pp. 102, Addison Wesley, Longman Publishing Co., Boston, MA, USA.

Haftka, R.T., Walsh, J.L. 1992. Stacking-sequence optimization for buckling of laminated plates by integer programming. AIAA Journal, 30: 814-819.

Harris, B. 1999. Engineering Composites Materials, $184 \mathrm{pp}$. The Institute of Materials. London, UK.

Hwang, S.F., Mao, C.P. 2001. Failure of delaminated carbon/epoxy composite plates under compression. Journal of Composite Materials, 35: 1634-1653.

Imran, M., Khan, R., Badshah, S. 2018a. Finite element analysis to investigate the influence of delamination size, stacking sequence and boundary conditions on the vibration behavior of composite plate. Iranian Journal of Materials Science and Engineering, 15: $0-0$.

Imran, M., Rafiullah, K., Badshah, S. 2018b. Vibration analysis of cracked composite laminated plate and beam structures. Romanian Journal of Acoustics and Vibration, 15: 3-13.

Imran, M. 2015. Pre-stress and free vibration optimization of composite ocean current turbine blade. International Journal of Science, Engineering and Innovative Research, 3: 1-5.

Johnson, S.M. 2006. Infrared Thermography and Thermoelastic Stress Analysis of Composite Materials and Structural Systems. M.S. Thesis, Georgia Institute of Technology, USA.

Kim, H.J., Hong, C.S. 1997. Buckling and postbuckling behavior of composite laminates with a delamination. Composites Science and Technology, 57: 557-564.

Kogiso, N., Watson, L.T., Gürdal, Z., Haftka, R.T., Nagendra, S. 1994. Design of composite laminates by a genetic algorithm with memory. Mechanics of Composite Materials and Structures: An International Journal, 1: 95-117.

Kyoung, W.M., Kim, C.G., Hong, C.S. 1998. Buckling and postbuckling behaviour of composite crossply laminates with multiple delaminations. Composite Structures, 43: 257-274.

Lombardi, M., Haftka, R.T., Cinquini, C. 1992. AIAA/ ASME/ASCE/AHS/ASC 33rd Structures, Structural Dynamics and Materials Conference, Dallas, TX, USA, Technical Papers, 13-15 April, 1992.

Morales, J.L., Nocedal, J., Wu, Y. 2011. A sequential quadratic programming algorithm with an additional equality constrained phase. IMA Journal of Numerical Analysis, 32: 553-579.

Muc, A., Gurba, W. 2001. Genetic algorithms and finite element analysis in optimization of composite structures. Composite Structures, 54: 275-281.

Nagendra, S., Haftka, R.T., Gurdal, Z. 1992. Stacking sequence optimization of simply supported laminates with stability and strain constraints. AIAA Journal, 30: 2132-2137.

Naik, G.N., Murty, A.K., Gopalakrishnan, S. 2005. A failure mechanism based failure theory for laminated composites including the effect of shear stress. Composite Structures, 69: 219-227.

Onoda, I.J. 1985. On the laminate configurations which maximize the axial buckling loads of composite cylindrical shells. 26 ${ }^{\text {th }}$ Structures, Structural Dynamics, and Materials Conference, pp. 800.

Parlapalli, M., Shu, D. 2004. Buckling analysis of twolayer beams with an asymmetric delamination. Engineering Structures, 26: 651-658. 
Reddy, A., Rehfield, L., Bruttomesso, R., Krebs, N. 1985. 26 $6^{\text {th }}$ Structures, Structural Dynamics, and Materials Conference, Orlando, FL, USA, pp. 804810, 15-17 April, 1985.

Sadagopan, D., Pitchumani, R. 1998. Application of genetic algorithms to optimal tailoring of composite materials. Composites Science and Technology, 58: 571-589.

Sargent, P.M., Ige, D.O., Ball, N.R. 1995. Design of laminate composite layups using genetic algorithms. Engineering with Computers, 11: 59-69.

Shukla, K., Nath, Y., Kreuzer, E., Kumar, K. 2005. Buckling of laminated composite rectangular plates. Journal of Aerospace Engineering, 18: 215223.

Sivakumar, K., Iyengar, N., Kalyanmoy, D. 1999. Optimum design of laminated composite plates undergoing large amplitude oscillations. Applied Composite Materials, 6: 87-98.

Soremekun, G., Gürdal, Z., Haftka, R., Watson, L. 2001. Composite laminate design optimization by genetic algorithm with generalized elitist selection. Computers and Structures, 79: 131-143.

Starnes, J., Knight, N., Rouse, M. 1985. Postbuckling behavior of selected flat stiffened graphite-epoxy panels loaded in compression. AIAA Journal, 23: 1236-1246.

Stevens, K., Ricci, R., Davies, G. 1995. Buckling and postbuckling of composite structures. Composites, 26: $189-199$.

Subramani, M.N. 2017. Review on hybrid composite materials and its applications. International Research Journal of Engineering and Technology, 4: 1921-1925.

Sultan, R.A., Guirguis, S.W., Younes, M.M., El-Soaly, E. 2013. Delamination detection by thermography.
International Journal of Engineering Research and Application, 3: 279-288.

Sultan, R., Guirguis, S., Younes, M., El-Soaly, E. 2012. Active infrared thermography technique for the non destructive testing of composite material. International Journal of Mechanical Engineering and Robotics Research, 1: 131-142.

Tafreshi, A. 2004. Delamination buckling and postbuckling in composite cylindrical shells under external pressure. Thin-walled Structures, 42: 13791404.

Tarján, G., Kollar, L., Sapkás, Á. 2009. Local web buckling of composite (FRP) beams. Journal of Reinforced Plastics and Composites, doi.org/ 10.1177/0731684409105083.

Tavares, S., Castro, P. 2017. An overview of fatigue in aircraft structures. Fatigue and Fracture of Engineering Materials and Structures, 40: 1510-1529.

Van der Burg, M. 2011. Plate Buckling in Design Codes: The Difference Between NEN 6771 and NEN-EN, Master Thesis, Delft University of Technology, TU Delft, The Netherlands, pp. 1-5.

Verette, R. 1970. Stiffness, strength and stability optimization of laminated composites. Northrop Aircraft Corporation, Report NOR-70-138, Hawthorne, CA, USA.

Wang, X., Dong, K. 2007. Local buckling for triangular and lemniscate delaminations near the surface of laminated cylindrical shells under hygrothermal effects. Composite Structures, 79: 67-75.

Yin, W.L., Fei, Z. 1988. Delamination buckling and growth in a clamped circular plate. AIAA Journal, 26: 438-445.

Yoshikawa, M., Yamauchi, H., Terai, H. 2008. Hybrid architecture of genetic algorithm and simulated annealing. Engineering Letters, 16: 339-345. 